As the practices selected were active in research, blood pressure control in these practices may be better than in the UK as a whole. Our analysis was based on the latest blood pressure recorded in the general practice records. This will have reflected several recordings of blood pressure in some cases and a single reading in other instances. This may have resulted in an overestimation of "true" blood pressure in this stroke population compared with measurements in the controlled setting of a study, but these are the readings on which management will be decided.

Current national and international guidelines may give appropriate advice for the management of blood pressure of younger patients who have had a recent cerebrovascular event. Unfortunately, these guidelines may act as an impediment to further research. We would urge that further evidence should be collected on the efficacy and adverse effects of intensive blood pressure lowering in representative populations before we implement this guidance in primary care.

Contributors: JM conceived and designed the study and analysed the data. RMcM assisted in the design and analysis and supervised the data collection from practices. $\mathrm{RH}$ was responsible for data collection. All authors contributed to the drafting of the paper. JM is the guarantor.

Funding: The research was supported by the Stroke Association. $\mathrm{RMcM}$ was funded by a Department of Health national primary care researcher development award.

Competing interests: None declared.

Ethical approval: South Birmingham Local Research Ethics Committee approved the study.
1 Intercollegiate Stroke Working Party. National clinical guidelines for stroke. 2nd ed. London: Royal College of Physicians of London, 2004.

2 Williams B, Poulter NR, Brown MJ, Davis M, McInnes GT, Potter JF, et al. Williams B, Poulter NR, Brown MJ, Davis M, McInnes GT, Potter JF, et al. ing party of the British Hypertension Society, 2004-BHS IV. J Hum Hypertens 2004;18:139-85.

3 Chalmers J, Todd A, Chapman N, Beilin L, Davis S, Donnan G, et al. International Society of Hypertension (ISH): statement on blood pressure lowering and stroke prevention. J Hypertens 2003;21:651-63.

4 Chobanian AV, Bakris GL, Black HR, Cushman WC, Green LA, Izzo JL Jr, et al. Seventh report of the Joint National Committee on Prevention, Detection, Evaluation, and Treatment of High Blood Pressure. Detection, Evaluation, and
Hypertension 2003;42:1206-52.

5 Hypertension 2003;42:1206-52. based blood pressure lowering regimen among 6,105 individuals with a previous stroke or transient ischaemic attack. Lancet 2001;358:1033-41.

Wennberg R, Zimmermann C. The PROGRESS trial three years later: time for a balanced report of effectiveness. BMJ 2004;329:968-71.

7 Mant J, McManus RJ, Hare R, Mayer P. Identification of stroke in the community: a comparison of three methods. $\mathrm{Br} J$ Gen Pract 2003;53:520-4.

8 Guevffier F, Bulpitt C, Boissel JP, Schron E, Ekbom T, Fagard R, et al. Antihypertensive drugs in very old people: a subgroup meta-analysis of Antihypertensive drugs in very old people: a subgroup meta-analysis of

randomised con

9 Lovett JK, Dennis MS, Sandercock PAG, Bamford J, Warlow CP, Rothwell PM. Very early risk of stroke after a first transient ischaemic attack. Stroke 2003;34:e138-42.

10 National Statistics. Mortality statistics: cause. London: Stationery Office, 2000. (Series DH2 No 26.)

11 West Midlands Public Health Observatory. Key health data for the West Midlands, 2001. Birmingham: Department of Public Health and Epidemiology, 2002. (Report No 31.)

12 Sproston K, Primatesta P, eds. Health survey for England 2003. Volume 1: cardiovascular disease. London: Stationery Office, 2004.

13 Office for National Statistics. Key health statistics from general practice 1998. London: Stationery Office, 2000.

14 Rothwell PM, Coull AJ, Giles MF, Howard SC, Silver LE, Bull LM, et al. Change in stroke incidence, mortality, case-fatality, severity, and risk factors in Oxfordshire UK from 1981 to 2004 (Oxford vascular study). Lancet 2004;363:1925-33.

(Accepted 10 January 2006)

doi 10.1136/bmj.38758.600116.AE

\title{
Intramuscular gluteal injections in the increasingly obese population: retrospective study
}

\author{
Andrew Charles Nisbet
}

\begin{abstract}
Aims To examine depth of subcutaneous fat at gluteal intramuscular injection sites.

Design Retrospective study.

Setting General hospital.

Participants 100 consecutive adults who had computed tomography of the pelvis.

Main outcome measures Minimum distance between the surface of the skin and the nearest edge of muscle at intramuscular injection sites.

Results 12 patients had a ventrogluteal site depth of more than $35 \mathrm{~mm}$, the maximum depth of a green needle, and 26 had a ventrogluteal depth of more than $25 \mathrm{~mm}$, the maximum depth of a blue needle. 43 patients had a dorsogluteal site depth of more than $35 \mathrm{~mm}$, and $72 \mathrm{had}$ a dorsogluteal depth of more than $25 \mathrm{~mm}$. The intramuscular site was likely to be deeper in women.

Conclusion Standard green and blue needles do not reach the gluteal muscles in a considerable number of patients.
\end{abstract}

\section{Introduction}

Studies of intramuscular injections have shown differences in peak plasma concentrations of narcotics and in perceived pain relief, depending on gluteal or deltoid injection site. ${ }^{1}$ Response levels to vaccination vary according to intramuscular injection site. ${ }^{2}$ Different responses depending on site have also been noticed for injections of antibiotics, ${ }^{3}$ insulin, and lignocaine. $^{4}$

Possible reasons for this variation in efficacy include different ratios of adipose to lean muscle tissue, greater blood flow in deltoid than gluteal muscle, ${ }^{5}$ and positional external compression of the gluteus. In a population that is increasingly overweight, these factors could become more exaggerated, leading overall to less effective intramuscular gluteal injections. Additionally, if the depth of fat is so great that the needle cannot reach the muscular layer in many patients, the average absorption of the drug in the population will be lower.

\section{Method}

Scans from 100 consecutive adults (39 men, 61 women; mean 47.8 (SD 11.3) years; range $22-65$ years) who had computed tomography scans of the pelvis

This article was posted on bmj.com on 8 March 2006: http://bmj.com/cgi/doi/10.1136/bmj.38706.742731.47
Jersey General Hospital, St Helier, Jersey JE2 3QS Andrew Charles Nisbet senior house officer in anaesthetics

Correspondence to: Le Grupe, Les Grupieaux, St Peter, Jersey JE3 7ED kaltarn@yahoo.co.uk

BMJ 2006;332:637-8 
were included in the study. I used automated computed tomography callipers to determine the minimum distance between the surface of the skin and the nearest edge of muscle at the ventrogluteal and dorsogluteal injection sites. (To determine the ventrogluteal site, place the ball of the opposing hand on the greater trochanter and index finger on the anterior superior iliac crest; form a $\mathrm{V}$ with the middle finger; the injection site is within the $\mathrm{V}^{6}$ The dorsogluteal site is the upper outer quadrant of the buttock. ${ }^{7}$ ) I also correlated the depth at both sites with age and sex of the patients.

\section{Results}

The depth of adipose tissue at the ventrogluteal site ranged from $2.5 \mathrm{~mm}$ to $62.6 \mathrm{~mm}$ (mean 19.0 (12.8) $\mathrm{mm})$. In 12 patients the depth was more than $35 \mathrm{~mm}$, the extent of a green needle, and in 26 the depth was more than $25 \mathrm{~mm}$, the extent of a blue needle. The depth at the dorsogluteal site ranged from $7.5 \mathrm{~mm}$ to $59.8 \mathrm{~mm}$ (mean $32.0(10.5) \mathrm{mm}$ ). In 43 patients the depth was more than $35 \mathrm{~mm}$, and in 72 the depth was more than $25 \mathrm{~mm}$.

Age was not correlated with dorsogluteal depth, but increasing age was related to increasing ventrogluteal depth ( $\mathrm{P}<0.01$, Pearson's correlation coefficient).

Site depth was markedly different in men and women. In the ventrogluteal site, 10 of $61(16 \%)$ women had a depth of $>35 \mathrm{~mm}$ and $22(36 \%)$ a depth of $>25 \mathrm{~mm}$, whereas 2 of $39(5 \%)$ men had a depth of $>35 \mathrm{~mm}$ and $4(10 \%)$ of $>25 \mathrm{~mm}$. In the dorsogluteal site, $35(57 \%)$ women had a depth of $>35 \mathrm{~mm}$ and $55(90 \%)$ of $>25 \mathrm{~mm}$, whereas $8(21 \%)$ men had a depth of $>35 \mathrm{~mm}$ and 17 (44\%) of $>25$ $\mathrm{mm}$. All differences between men and women were significant $\left(\mathrm{P}<0.01, \chi^{2}\right.$ test, except $\mathrm{P}<0.05$ for ventrogluteal depth $>35 \mathrm{~mm}$ ).

\section{Discussion}

Due to the depth of fat, intramuscular injections with large (green) needles into the anterior gluteal site in this sample would be subcutaneous in $12 \%$ of patients ( $16 \%$ of women and $5 \%$ of men), and for injections with smaller (blue) needles in $26 \%$ (36\% of women and $10 \%$ of men). In the posterior gluteal site, large needles will fail to reach muscle in $43 \%$ ( $57 \%$ of women and

\section{What is already known on this topic}

The gluteal site can be less effective for intramuscular injections than other sites, such as deltoid

\section{What this study adds}

The gluteal muscles are beyond the reach of standard green and blue needles in a significant minority of patients

$21 \%$ of men), and small needles will fail in $72 \%$ (90\% of women and $44 \%$ of men).

The number of patients used in this study was small, and they were recruited only from a local population and did not include the extremes of age. Although the depth of their gluteal intramuscular injection sites may vary from the national average, this study shows that in a significant minority of patients the standard green or blue needles, which are the normal method of delivery, will fail to reach muscle. In highly obese populations, the depth could be expected to be even greater than that shown here.

As previous studies have shown low efficacy of gluteal intramuscular injections, this route should be avoided for most drugs. If alternative routes are not possible, using longer needles should be considered.

Contributors: ACN is the sole contributor and is guarantor. Funding: None.

Competing interests: None declared.

Ethical approval: Not required.

1 Grabinski P, Kaiko RF, Rogers AG, Houde RW. Plasma levels and analgesia following deltoid and gluteal injections of methadone and morphine sia following deltoid and gluteal

2 Lindsay KL, Herbert DA, Gitnick GL. Hepatitis B vaccine: low postvaccination immunity in hospital personnel given gluteal injections. Hepatology 1985;5:1088-90

3 Vukonovich RA, Brannick LJ, Sugerman AA, Neiss ES. Sex differences in the intramuscular absorption and bioavailability of cephradine. Clin Pharmacol Ther 1975;18:215-20.

4 Cohen LS, Rosenthal JE, Horner DW Jr, Atkins JM, Matthews OA, Sarnoff SJ. Plasma levels of lidocaine after intramuscular administration. Am J Cardiol 1972;29:520-3.

5 Evans EF, Proctor JD, Fratkin MJ, Velandia J, Wasserman AJ. Blood flow in muscle groups and drug absorption. Clin Pharmacol Ther 1974;17:44-7.

6 Grabinski PY. IM injections-deltoid or gluteal site? PRN Forum 1983;2:2-3.

7 Greenway, K. Using the ventrogluteal site for intramuscular injections. Nursing Standard 2004;18(25):39-42.

(Accepted 21 November 2005)

doi $10.1136 /$ bmj.38706.742731.47

\section{An instrumental history of medicine}

While holding a Langenbeck retractor for my consultant for the umpteenth time, I began to wonder who it was named after and what this figure contributed to surgery. My curiosity piqued, I set off to the Wellcome Institute one afternoon and uncovered the fascinating history of the Langenbeck retractor.

Conrad Johann Martin Langenbeck (1776-1851) was professor of surgery and anatomy in Gottingen. He was an infamous, accomplished surgeon, known for his speed. It is said that a colleague, in turning away to take a pinch of snuff, missed

Langenbeck perform a shoulder amputation.

His most famous operation was the first vaginal hysterectomy in 1813. It was carried out on a 50 year old multiparous woman, possibly with cancer of the cervix. He performed this feat without anaesthesia or an assistant. At one point, he was left clutching the bleeding area in his left hand, holding one end of a ligature with his teeth, and tying the other end with his right hand. Langenbeck claimed a careful dissection so as not to open the peritoneal cavity. There was considerable haemorrhage, but, amazingly, the patient survived, revived by a splash of water to the face. After the operation, however, the specimen was lost, and Langenbeck's achievement was doubted by the medical fraternity until, 26 years later, the patient died and a postmortem examination confirmed his statement.

Rajvinder Khasriya senior house officer, obstetrics and gynaecology, St Thomas'Hospital,London (rajuinderkhasriya@hotmail.com) 